\title{
LA IMPUTABILIDAD DISMINUIDA: UNA CATEGORÍA PROBLEMÁTICA DEL DERECHO PENAL
}

\author{
The diminished criminal liability: a problema category of criminal law
}

Frank Harbottle Quirós*

\begin{abstract}
Resumen: El presente artículo contiene un estudio histórico, normativo y doctrinario sobre la imputabilidad disminuida como elemento de la culpabilidad penal. Se expone, en un primer apartado, el surgimiento de esta figura hasta su incorporación formal en las legislaciones y en los procesos judiciales. Luego se examinan los diversos planteamientos en relación con la respuesta que debe ofrecer el derecho penal para los supuestos en que se demuestra que una persona cometió un hecho sancionado como delito, actuando bajo un estado de imputabilidad disminuida. Finalmente, se propone la eliminación de este polémico concepto de la teoría del delito a partir de una redefinición de los términos imputabilidad e inimputabilidad.
\end{abstract}

Palabras clave: derecho penal, imputabilidad, imputabilidad disminuida, inimputabilidad, respuesta penal.

\begin{abstract}
This article contains a historical, legal and doctrinal study about the diminished criminal liabilityas an element of criminal culpability. It is exposed in the first section, the appearance of this figure until it was formally incorporated in legislation and in judicial proceedings. Then, the different approaches are examined in relation to the response to be provided by criminal law to cases in which it is shown that a person committed a crime, acting under a state of diminished criminal liability.Finally, it is proposed to eliminate this controversial concept of the theory of crime based on a redefinition of the terms criminal liability and non-imputability.
\end{abstract}

Keywords: criminal law, liability, diminished criminal liability, non-imputability, criminal response.

\section{Introducción}

La enfermedad mental tradicionalmente ha sido un factor asociado a la delincuencia. Sin embargo, en la actualidad, no pueden extraerse conclusiones definitivas al relacionar la delincuencia y los trastornos psicopatológicos. No todo

\footnotetext{
* Abogado. Licenciado en Derecho con graduación de honor de la Universidad de Costa Rica. Máster en Criminología de la Universidad Estatal a Distancia. Especialista en Derechos Fundamentales y Garantías Constitucionales en el Derecho Penal y Procesal Penal, Universidad de Castilla-La Mancha, España. Diploma en Ciencias Criminales y Dogmática Penal Alemana, GeorgAugust Universität Göttingen, Alemania. Defensor Público, actualmente Letrado de la Sala de Casación Penal de la Corte Suprema de Justicia de Costa Rica. Profesor de la Facultad de Derecho de la Universidad de Costa Rica. Docente del Colegio de Abogados y Abogadas de Costa Rica. Correo electrónico: frank.harbottlequiros@ucr.ac.cr.
}

Este artículo fue recibido el 12 de julio de 2016, siendo aprobada su publicación el 28 de septiembre de 2016. 
criminal o delincuente es un enfermo mental, ni todo enfermo mental comete actos delictivos (López y Núñez, 2014:881).

En términos generales suele decirse que los “delincuentes"son recluidos en centros penitenciarios (cárceles), mientras que los enfermemos mentales o mal llamados "locos" son internados en instituciones como los hospitales psiquiátricos.

Cuando la "locura" y la "delincuencia" se articulan surge un tema apasionante dentro del campo del derecho penal: la comisión de un hecho delictivo por una persona con un trastorno o anomalía mental.

Esto nos lleva a pensar en al menos tres escenarios en lo que respecta a la capacidad mental de una persona para el momento en que incurre en un hecho delictivo:(i) ausencia de capacidad (inimputabilidad); (ii) plena capacidad (imputabilidad); (iii) disminución en su capacidad (imputabilidad disminuida).

El presente trabajo se centrará en el último supuesto, es decir, cuando el sujeto activo al momento de llevar a cabo una conducta delictiva posee de forma incompleta la capacidad de comprender el carácter ilícito del hecho o de determinarse de acuerdo con esa comprensión a causa de un trastorno o anomalía mental.

En las próximas líneas se presenta un recuento de la evolución histórica de la imputabilidad disminuida. Luego se procede con el estudio de las distintas respuestas que ha ofrecido el Derecho Penal frente a esta categoría problemática. Finalmente, se expone la propuesta central de este artículo, a saber, la eliminación de este instituto del ordenamiento jurídico.

\section{Antecedentes históricos de la imputabilidad disminuida}

En la primera mitad del siglo XIX, autores como Kleinschrod y von Feuerbachse se pronunciaron de manera incipiente en relación con lo que denominaron imputabilidad limitada o aminorada (Yáñez, 1970: 307-308). Sin embargo, la figura que hoy conocemos como imputabilidad disminuida surge como consecuencia del desarrollo de las ideas de la Escuela Clásica y la Escuela Positiva, específicamente en lo relativo al dilema "libertad-determinismo".

Es hasta finales del siglo XIX que esta figura pasa a regularse en diversas legislaciones y comienza a aplicarse en los procesos judiciales de distintos países del orbe. disminuida.

De seguido se exponen los antecedentes históricos de la imputabilidad 


\section{a) La Escuela Clásica}

La Escuela Clásica, cuyo mayor representante fue Francesco Carrara (1805-1888), buscó la causa del distinto tratamiento de imputables e inimputables en la tesis del libre arbitrio y la culpabilidad moral, esbozada por Aristóteles según la cual, el ser humano al utilizar sus facultades intelectivas y volitivas es libre para elegir. En el supuesto de que cometa un delito usando o abusando de esta libertad es responsable por imputable de este. En cambio, si el sujeto carece de estas facultades se considera que no es capaz hacer uso de esa libertad y, por lo tanto, no puede ser responsable por inimputable de sus actos (Muñoz, 1998:28).

Como consecuencia de ese punto de vista, quedan excluidos no solo de la pena, sino del derecho penal aquellos sujetos que cometen un delito en condiciones de alteración de sus facultades mentales que les priven de la capacidad de comprender y de determinarse (Soler, 1989:40).

Para el clasicismo penal la imputabilidad, como primer presupuesto de la pena era susceptible de medirse cuantitativamente, de ahí que se hablase de imputabilidad agravada y atenuada, completa e incompleta, total y parcial o semiimputabilidad (Yáñez, 1970:307). De acuerdo con esta concepción gradual de las bases de la imputabilidad (conciencia o libertad más o menos disminuidas), se entendió que en estos casos debía corresponder una responsabilidad y una pena atenuada (Díaz, 1965:175).

Con la doctrina clásica, se consideró a la persona normal como totalmente responsable y la completamente anormal totalmente irresponsable, estimándose que quien padecía de un trastorno mental incompleto debía ser responsable solo de una manera atenuada (Puig, 1955:53).

La enfermedad llegó a verse como manía intelectual (con delirio), manía moral (sin delirio) y manía parcial, limitándose al aspecto morboso o enfermedad, no haciendo extensiva la idea a situaciones que no estén relacionadas con la "locura" (Vela, 1988:296).

Este planteamiento, basado en el libre arbitrio fue aceptado casi unánimemente y se constituyó en la base teórica de la imputabilidad. No obstante, posteriormente surgieron críticas contra el mismo, porque se basaba más en un postulado metafísico indemostrable que en un dato empíricamente verificable. De esta forma, el progreso científico natural y concretamente de la psiquiatría del siglo XIX, fueron los encargados de cuestionar esta tesis.

\section{b) La Escuela Positiva}

A mediados del siglo XIX se empiezan a aplicar métodos de observación científica al crimen para determinar las causas de la criminalidad, dándose el auge de la llamada Escuela Positiva cuyos mayores representantes fueron Cesare 
Lombroso, Enrico Ferri y Garófalo, quienes llegaron a ver al delincuente como un hombre anormal, por sus anomalías orgánicas y psíquicas, hereditarias y adquiridas (Velásquez, 1997:8-9).

Surge así la escuela positivista italiana como reacción contra al punto de vista clásico. La negación metafísica del principio del libre albedrío, lleva a la afirmación también metafísica del determinismo (Soler, 1989:41).

Dentro de los sujetos peligrosos, se ubicó a los delincuentes que, no estando ni completamente enfermos ni totalmente sanos, pertenecen a lo que en el libro El Crimen y la locura (1874) Maudsley llamó "zona intermediaria", y que distinguió Lombroso con el nombre de "mattoides". De acuerdo con Ferri: "... estos medio locos son los que cometen los crímenes sangrientos más atroces y más repugnantes, con una frialdad que procede justamente de su organización patológica..." (Ferri, 2005:166).

De esta forma, el positivismo criminológico emprende una lucha contra el reconocimiento de la imputabilidad disminuida como atenuante, al considerarse que las personas con menor culpabilidad eran más peligrosas que las restantes y, por lo tanto, era absurdo que se les colocara en una situación de privilegio (sanciones atenuadas) con visible menosprecio de los intereses de la sociedad que reclamaba una defensa eficaz (Zaffaroni, 2002:708).

Desde esta perspectiva, la rigurosa separación de los delincuentes en responsables y no responsables llega a visualizarse como peligrosa, al verse la imputabilidad como algo relativo.

Con Franz von Liszt se abre un mayor campo a la imputabilidad disminuida. Llegan a contemplarse excitaciones que se traducen en reacciones no limitándose a los estados morbosos o francas enfermedades, disponiéndose por los juzgadores de un material más manejable sin la drástica posición de responsables e irresponsables o, lo que es igual, un estado intermedio en el que pueden encontrar acomodos casos concretos de especial presentación (Vela, 1988: 296-297).

\section{c) Aparición en la legislación y en los procesos judiciales}

Como se adelantó, en el siglo XIX se dio una pugna entre dos tendencias contrapuestas en torno a la semiimputabilidad.

Por una parte resultaba lógico que muchos deterministas se opusieran a que la imputabilidad disminuida llevara consigo una disminución en la cantidad o gravedad de la pena a imponer, por las mismas razones que abominaban de la pena ordinaria como respuesta frente a los delitos cometidos por sujetos imputables, ya que ni una ni otra sanción eran adecuadas para cumplir las finalidades de defensa social asignada al Derecho Penal. Sin embargo, también desde las filas positivistas podía defenderse la mitigación del castigo en algunos 
casos de semiimputabilidad, en la medida en que la influencia de determinados motivos sobre el comportamiento del agente pudiera justificar el considerarlo menos peligroso (Martínez, 2005:44).

La polémica sobre la imputabilidad alimentó también el debate acerca del sentido del concepto "libertad", en razón de que ante las críticas positivistas a la misma como fundamento de la imputación de responsabilidad, los defensores de la escuela clásica se vieron obligados a precisar sus presupuesto de partida y florecieron las disquisiciones en torno a los distintos significados del término "libertad", así como a la idoneidad de este concepto para ser graduado a la posibilidad o no de hablar de libertad "relativa", "condicionada" o "disminuida", etc. (Martínez, 2005:46).

Conforme lo apunta Urruela (2004:185) es hasta finales del siglo XIX donde se incorpora el concepto de imputabilidad disminuida en los distintos códigos penales, siendo pioneros en su reconocimiento expreso el Código Penal alemán de 1871 y el italiano, de 1889. A partir de este momento se produce una admisión generalizada de la semiimputabilidad en los diferentes textos legislativos.

Se afirma que el primer diseño de código penal que integró sistemáticamente penas y medidas de seguridad fue el Anteproyecto de 1893 del Código Penal suizo, obra de Carl Stoos, el cual preveía respecto de los semiimputables que hubieran cometido delitos graves el someterlos a tratamientos curativos en establecimientos adecuados antes del cumplimiento de la pena contemplándose que el tiempo trascurrido en el establecimiento debía abonarse después a los efectos del cumplimiento de la pena (Martínez, 2005:49).

El tema de la "semilocura" fue ampliamente debatido en Europa. En Francia la "responsabilité atténuée" se desarrolló a partir de un fallo de la Corte de Casación de 1885 que afirmaba que no existía violación del artículo 64 del Código Penal francés por el hecho de moderar la pena en atención al limitado discernimiento. Por su parte, en sentencias de los años 1891 y 1899, se admitió la posibilidad de locura o de imbecilidad incompletas (Ferreirós, 2007:194).

Los cambios legislativos en modo alguno mermaron el debate doctrinario en torno a la imputabilidad disminuida.

Autores como Edmund Mezger consideraron que la regulación de la imputabilidad parcial debía incluirse en los preceptos de determinación de la pena y no en los generales de la imputabilidad a modo de figura intermedia (Díaz, 1965:180), quedando en manos del juez la decisión de si este tipo de imputabilidad merece o no la atenuación de la pena (Pavón, 1983:124-125).

Reinhart Maurach por su parte hizo hincapié en cuanto a que la imputabilidad disminuida no es un caso "límite" en el que se está en duda de si el autor es imputable o inimputable, sino de una situación en que el autor es 
imputable, pero para alcanzar el grado del conocimiento y dirección de un sujeto anímicamente normal debe esforzar su voluntad, por lo que cabe aplicar el postulado de que la imputabilidad disminuida debe constituir una obligatoria causa de atenuación de la pena (Pavón, 1983:124-125). Wilmanns la conceptualizó desde una perspectiva puramente cualitativa (Yáñez, 1970:310), en tanto Hans Welzel consideró que si las facultades solo son limitadamente afectadas, no pueden producir sino un efecto disminuido en la capacidad de culpabilidad (Vela, 1988:298-299).

Para el año 1906 el instituto de la imputabilidad disminuida pasó a tomar un mayor protagonismo gracias a la obra de Bernard Grasset "Semi-locos y semiresponsables" quien, bajo esos nombres, cobijó la cuarta parte de los trastornos psíquicos que transitaban por los más variados derroteros de la psiquiatría: neurosis, personalidades psicopáticas, alcoholismo crónico, debilidad mental, deterioros seniles y preseniles, defectos esquizofrénicos (esquizofrenias residuales), posconmociones de cráneo, posencefalitis, epilepsias (equivalentes), toxicomanías, encefalopatías, afasias, etc. (Cabello, 1981:180).

Frente a la tesis maximalista de algunos médicos que propugnaban en estos casos la absolución por enfermedad metal se fue imponiendo poco a poco, tanto en el estamento médico como en el judicial, la opinión de que lo más adecuado era aplicar una atenuación de la responsabilidad (Martínez, 2005: 42).

Aún y cuando se dice que en Alemania desde hace un siglo se alcanzó un consenso en torno a que, a pesar de mantenerse formalmente la denominación "imputabilidad disminuida", lo que en realidad se ve disminuido es el grado de responsabilidad o de culpabilidad de la persona y no la imputabilidad, la cual, en la medida en que se define como capacidad, solo puede existir o no por lo que los "semiimputables" son individuos imputables a los cuales se reconoce una atenuación de la responsabilidad (Martínez, 2005:51) lo cierto es que las discusiones surgidas en el siglo XIX en torno a la imputabilidad disminuida -indistintamente de su denominación- aún se mantienen vigentes, sin que exista consenso en la doctrina sobre la conveniencia de contemplar dicha fórmula dentro de los ordenamientos jurídicos de los distintos países.

Bajo esta misma tesitura la respuesta que debe ofrecer el Derecho Penal cuando una persona actúa bajo un estado de imputabilidad disminuida constituye otro tópico sobre el que se han presentado disparidad de criterios. Este tema precisamente se abordará a continuación.

\section{Respuesta penal ante la imputabilidad disminuida}

En la actualidad, la mayoría de los países han optado por un Derecho Penal con un sistema de doble vía: se prevén penas, como forma de reacción frente a los 
delitos cometidos por sujetos imputables y, medidas de seguridad, para los cometidos por inimputables.

Sin embargo a nivel doctrinal no ha sido pacífica la discusión en cuanto a la respuesta penal para los casos en que se determina que la persona denunciada actuó bajo un estado de imputabilidad disminuida. De seguido se exponen las tres alternativas que se han planteado.

\section{a) La imposición de una pena de prisión atenuada}

Quienes se adhieren a esta posición, afirman que la imputabilidad disminuida implica que el autor es capaz de entender el carácter ilícito del hecho o de determinarse de acuerdo con esa comprensión pero, para lograr ese resultado, debe poner en práctica una fuerza de voluntad mucho mayor que un sujeto mentalmente normal. Por ello, la consecuencia debe ser la imposición de una pena atenuada (Castillo, 2010:497-498).

Otros autores como Morales (2008:128) sostienen que la imputabilidad disminuida solo puede entenderse como concepto compuesto, en el sentido de imputabilidad subsistente o reducción de la capacidad de culpabilidad. Al estar las capacidades tan solo limitadas y no ausentes, lo que cabe es una disminución del reproche.

El Código Penal de la Nación Argentina ${ }^{1}$ (2013, Art. 34, inciso 1) señala que no es punible la persona que en el momento del hecho, ya sea por insuficiencia de sus facultades, por alteraciones morbosas de sus facultades o por su estado de inconsciencia, error o ignorancia, no haya podido comprender la criminalidad del acto o dirigir sus acciones, ante lo cual Zaffaroni (2002:708-709) comenta que dicho numeral reconoce la posible disminución de la imputabilidad y, en ese caso por haber menor culpabilidad, debe darse una atenuación obligatoria en la pena que se impone.

En cuanto a Chile, Leyton (2014: 30) indica que el ordinal 11 numeral $1^{\circ}$ del Código Penal de dicho país considera como circunstancia atenuante cuando no se cumplan todos los requisitos para eximir de responsabilidad penal al sujeto, de acuerdo a las exigencias del artículo 10. A su vez, el artículo 73 permite la rebaja de pena hasta en tres grados.

Por su parte, el Código Penal alemán ${ }^{2}$ (1999, art.20) estipula que actúa sin culpabilidad la persona que, en la comisión del hecho por razón de un trastorno mental, de una consciencia alterada o por razón de deficiencia mental o de otras anomalías mentales graves, esté incapacitada para apreciar la injusticia del hecho o

\footnotetext{
${ }^{1}$ Código Penal de la Nación Argentina (2013: 26).

${ }^{2}$ Código Penal Alemán (1999: 9).
} 
para actuar con esta intención y, adiciona el art. 21 que si la capacidad de la persona autora para apreciar la injusticia del hecho o para actuar con esta intención en el momento de la comisión del, ismo por las razones señaladas en el Art. 20 se ve notablemente reducida, la pena puede atenuarse.

\section{b) La imposición de una pena de prisión y de medidas de seguridad}

El Código Penal Tipo para Latinoamérica fue el resultado de decisiones tomadas en varios congresos celebrados en los años 1965, 1969, 1970 y 1971 en distintos países de latinoamérica.

Esta normativa reguló la imputabilidad disminuida en el artículo 20 y la inimputabilidad en el numeral 19.

Para aquel momento, se consideró pertinente contemplar la imposición de una pena no menor de un tercio del mínimo ni mayor de un tercio del máximo de la establecida por la ley para el correspondiente delito al agente que por causa de enfermedad mental, de desarrollo psíquico incompleto o retardado, o de grave perturbación de la conciencia en el momento de la acción u omisión no tuviese plena capacidad de comprender el carácter ilícito del hecho o de determinarse de acuerdo con esa comprensión. Adicionalmente, se apuntaba que en caso de que la imposición de la pena se considerase perjudicial para el debido tratamiento del agente por mediar causas patológicas, solamente debía aplicarse una medida de seguridad curativa. Finalmente enuncia que, en los demás casos, es posible aplicar una pena disminuida, una medida curativa o ambas en el orden señalado por el Juez. ${ }^{3}$

Para autores como Calderón, la solución acogida por el Código Penal Tipo (no predeterminar de manera rígida como única opción judicial la atenuación de la pena) es la que mejor se acomoda a las circunstancias concretas, resultando aconsejable diferir al prudente arbitrio del juez la alternativa entre disminuir la pena, imponer la medida de aseguramiento o acoger el sistema del doble binario, aplicando sucesivamente las dos, en el orden que se considere más efectivo para el logro de la readaptación del agente (Calderón, 1996:68).

El Código Penal español vigente ${ }^{4}$ en el numeral 99 admite la posibilidad de que concurran penas y medidas de seguridad privativas de libertad, artículo que debe ser analizado en concordancia con el 104, el cual establece que en los supuestos de eximente incompleta (circunstancia atenuante) en relación con los números $1^{\circ}, 2^{\circ}$ y $3^{\circ}$ del artículo 20 el Juez o el Tribunal podrá imponer, además de la pena correspondiente, las medidas previstas en los artículos 101, 102 y 103.

\footnotetext{
3 Código Penal tipo para Latinoamérica (1973: 29-30).

${ }^{4}$ Código Penal y Legislación Complementaria (2015: 31-33).
} 
En relación con la legislación española, Arias indica que las eximentes incompletas por semiimputabilidad, semiinimputabilidad, imputabilidad o capacidad de culpabilidad disminuida comprenden aquellos casos (artículo 21.1. del Código Penal) en que, si bien en el sujeto no llega a concurrir una causa de exención completa de la responsabilidad del art. 20.1, 2, 3 del Código Penal, la disminución de la capacidad de culpabilidad excede notablemente de la concurrencia de una mera circunstancia atenuante. El fundamento de estas circunstancias atenuantes privilegiadas se encuentra en que la imputabilidad no es estática o monolítica, sino que admite graduaciones de suerte que, entre la plena imputabilidad y la total inimputabilidad, existen situaciones que hacen precisa una respuesta punitiva acertada a esa capacidad de culpabilidad disminuida, sin perjuicio de que quepa aplicársele, en su caso, alguna medida de seguridad con arreglo al sistema vicarial implantado en el Código Penal español (Arias, 1996: 201).

Se afirma que podría darse el caso de que un sujeto semiimputable devele que es también portador de peligrosidad criminal por lo que, solo bajo esta circunstancia, el Juez o Tribunal podría evaluar la posibilidad de imponerle, además de la pena adecuada a la magnitud de su -reducida- culpabilidad, una medida de seguridad con miras a la consecución de ciertos fines de prevención especial. Dado que, en principio, la pena para los semiimputables tendrá que atenuarse en uno o dos grados, la duración de la misma, finalmente se aproximará en mayor o menor medida al límite inferior de la pena abstracta establecida en la ley penal, por lo que, de hecho, cabe la posibilidad de que el juzgador imponga una medida de seguridad cuya duración se aproxime al límite máximo de la pena abstracta establecida en el CP para el delito concreto (p. ej. para el delito de asesinato podría establecerse una pena privativa de libertad de quince años $y$, conjuntamente, una medida de seguridad -también privativa de libertad- de veinte años de duración) (Armaza, 2013: 60).

Con respecto a la posibilidad de imponer al sujeto tanto una pena atenuada como una medida de seguridad, Carmona ha indicado que ello puede acarrear consecuencias prácticas indeseables, pues resulta absurdo tanto aplicar primero la pena, con lo cual puede empeorar la situación del enfermo y a continuación la medida con objeto de conseguir su curación, como aplicar en primer lugar la medida de seguridad y a continuación la pena, ya que si el enfermo se ha curado puede recaer si se le somete a continuación al cumplimiento de la pena (Carmona, 1995: 213).

\section{c) La imposición de medidas de seguridad}

Según lo apunta Náquira (1987:167), el tema de la imputabilidad e inimputabilidad en el Código Penal Tipo para Latinoamérica se encuentra tratado en la Sección A, Capítulo III (Artículos 19 al 23) y fue objeto de estudio y de decisiones en la Segunda, Cuarta, Quinta y Sexta Reuniones Plenarias celebradas en México (1965), Venezuela (1969), Colombia (1970) y Brasil (1971). 
El Código Penal costarricense vigente, Ley 4573 del 4 de mayo de 1970, comenzó a regir antes que se aprobara la versión final del Código Penal Tipo para Latinoamérica estableciendo, en el artículo 98 inciso 1,5 que ante el supuesto de imputabilidad disminuida debe imponerse una medida de seguridad.

La Sala Constitucional de la Corte Suprema de Justicia de Costa Rica, mediante sentencias $\mathrm{n}^{\circ} 2009-04555$ de las 08:23 horas del 20 de octubre de 2009; 2009-10383 de las 13:39 horas del 26 de junio de 2009; 2010-12189 de las 17:12 horas del 20 de julio de 2010 y 2010-17720 de las 14:32 horas del 26 de octubre de 2010, ratificó que las medidas de seguridad resultan procedentes para las personas con imputabilidad disminuida.

Según lo expone Chinchilla, en términos generales la doctrina parte de que las situaciones del imputable y de quien actúa con imputabilidad disminuida no son equiparables resultando factible la imposición de una pena facultativamente disminuida por el juez frente a este último supuesto, argumentos que considera técnicamente correctos y dogmáticamente mayoritarios; sin embargo, la aplicación de este supuesto no es viable en Costa Rica, pues no han sido contemplados por la legislación de modo tal que proceder de así sería aplicar analógicamente la ley en perjuicio del acusado, pues sería posibilitar la sanción para supuestos no previstos expresamente; por lo que en aras de garantizar el principio de legalidad, lo procedente es imponer una medida de seguridad para quien actúa bajo un estado de imputabilidad disminuida (Chinchilla, 2010:148).

Se ha dicho que el Código Penal de Costa Rica distingue entre "inimputabilidad" e "imputabilidad disminuida" como formas de incapacidad, resultando inútil esta separación, pues basta que las capacidades de comprensión del ilícito y de determinación según esa comprensión estén reducidas para que no haya plena imputabilidad. Por esta razón es que al inimputable y al "imputable disminuido" se les impone la misma consecuencia jurídica: una medida de seguridad, si se les diagnostica su peligrosidad criminal (Navas, 2011:269).

Vemos entonces, que las respuestas que ha ofrecido el Derecho Penal son variadas. En la actualidad se sigue discutiendo cuál es la mejor forma de articulación entre uno y otro tipo de consecuencia jurídica en el caso de la imputabilidad disminuida.

En fin, el debate acerca de si existen en verdad diferencias sustanciales entre ambas clases de consecuencias jurídico-penales o se trata únicamente de distintas "etiquetas" para una misma reacción punitiva del Estado no está tampoco cerrado (Martínez, 2005:46).

La respuesta penal ante la ausencia o disminución de la capacidad mental posee plena vigencia en la actualidad a raíz de los resultados que han

\footnotetext{
${ }^{5}$ Código Penal de Costa Rica (2015: 72).
} 
arrojado las neurociencias no escapando a este panorama el estudio de la imputabilidad disminuida.

Precisamente esta temática será presentada en el apartado que sigue el cual culmina con la propuesta de eliminación del concepto de imputabilidad disminuida de la teoría del delito a partir de una redefinición de los términos imputabilidad e inimputabilidad.

\section{La imputabilidad disminuida: presente y futuro}

En el concepto de capacidad de culpabilidad subyace -y esa se supone que es la base del reproche penal- un concepto de libre voluntad, de libertad de decisión o de libre albedrío. Solamente existe autorización para sancionar con una pena, con una sanción penal a quien tiene cierta libertad para decidir. Esta libertad está asociada, a su vez, con una capacidad para comprender. Esta idea presupone que, en los casos en que no existe una enfermedad mental o un grave trastorno de la conciencia, el sujeto actuante tiene la libertad para decidir, tiene libre voluntad. Si se le sanciona es porque teniendo esa libertad para decidir, decidió actuar en contra de lo que establece el derecho. La idea de la libertad de decisión como rasgo esencial del ser humano está en el centro de una enorme controversia, siendo un tema muy discutido en la actualidad en países como Alemania (Chan, 2013:97-98).

Hoy es posible pensar en tres aproximaciones al problema libre albedrío-determinismo. La librealbedrista, según la cual existe una libertad total en la toma de decisiones por parte del individuo. A esta se opone la concepción determinista fuerte que a su vez afirma que no existe tal cosa como el libre albedrío, pues no se trata más que de una ilusión. Una tercera aproximación, la compatibilista, asume por su parte que libre albedrío y determinismo pueden coexistir (Arocena, Balcarce y Cesano, 2015:40-41).

El viejo debate sobre determinismo e indeterminismo se ha vuelto extraordinariamente actual a la luz de las últimas investigaciones llevadas a cabo en el campo de la neurobiología, que parecen conducir a la conclusión de que en realidad ningún ser humano tiene ante sí la elección entre actuar bien o mal moralmente, ya que la libertad de voluntad es una mera ilusión y el mal un fenómeno biológico que reside en el cerebro (Demetrio, 2015:39-40).

Cabe preguntarse ¿pueden, las investigaciones en neurociencias introducir algún aporte en el campo de la capacidad de culpabilidad y, de manera concreta, en lo que respecta a la imputabilidad disminuida?

La respuesta pareciera ser afirmativa. Los avances en el campo de las neurociencias han abarcado conocimientos que, en la época de nacimiento de los 
términos "semi-locos", "semi-alienados", "semi-responsables" y "semiimputables" todavía no existían.

Hoy se ha llegado a descubrir los mecanismos del cerebro que se activan en la toma de decisiones de las personas y cómo las funciones de razonar y decidir pueden ser ubicadas en determinadas regiones cerebrales.

En la actualidad, es necesario tener en cuenta en la elaboración del concepto de ciertas causas de exclusión de la culpabilidad -concretamente la inimputabilidad, en su presupuesto biológico- ciertas investigaciones provenientes de las neurociencias; como lo son aquellas referidas a los daños que puede haber sufrido el agente en los lóbulos frontales y su incidencia en la capacidad de autocontrol (Arocena, Balcarce y Cesano, 2015:103).

Surgen varias interrogantes: ¿Hasta dónde llega la libertad de decisión de quien actúa bajo un estado de imputabilidad disminuida?, ¿Qué significa una disminución en las facultades mentales? Si la persona ha actuado con una "libertad parcial o disminuida", ¿Por qué resulta válido imponerle una pena (aunque sea atenuada)?, ¿Es en realidad el inimputable disminuido un sujeto peligroso?, ¿Hay trastornos mentales que pueden generar una imputabilidad disminuida y otros no?

Quienes sostienen que la imputabilidad disminuida debe mantenerse vigente afirman que la capacidad mental de las personas tiene grados, por lo que este concepto debe estar en medio de la imputabilidad y de la inimputabilidad.

La imputabilidad o capacidad de culpabilidad notablemente disminuida se ve como un caso de imputabilidad y no como una forma autónoma de "semiimputabilidad", pues el sujeto aún es capaz de comprender el injusto del hecho y de actuar conforme con esa comprensión (Roxin, 1997:839), por lo que resulta procedente una atenuación del reproche (Bacigalupo, 1999:455-456), sobre todo para para hacer referencia a distintos trastornos como los retrasos mentales en sus diferentes grados, demencias incipientes, intoxicaciones, epilepsias, control de los impulsos, entre otros (Juárez, 2010:40).

Para los detractores, el término semialienación es vago e impreciso. Conlleva al riesgo médico forense de que se convierta en el gran recipiente de las dudas diagnósticas donde irían a parar todos los casos de indefinida filiación psicopatológica, pasando a ser el comodín de la incertidumbre y la fácil solución jurídica de todos aquellos casos lindantes entre la culpabilidad y la peligrosidad (Cabello, 1981:187).

Se ha dicho que este concepto presenta problemas siendo sistemáticamente incorrecto, por cuanto la imputabilidad como tal, es un estado personal que determina una cierta consecuencia (la incapacidad de autodeterminación) y, por consiguiente, no admite graduaciones. El sujeto es o no es capaz de comprender lo injusto y actuar en consecuencia; el factor intelectual, desde luego, es indivisible, 
porque no existe un "entender a medias"; en cuanto al volitivo como capacidad personal subsiste aunque se encuentre limitado o bien no existe del todo (Cury, 2007:32). Una persona no puede ser medio insana o medio loca. Sería impropio calificar a un sujeto como semialienado (Zazzali, 2015:54).

En ese sentido lleva razón Yáñez cuando afirma que la defectuosidad del sistema de la imputabilidad disminuida se debe, sobre todo, a la dificultad de determinar las características que delimitan los casos que deben encajarse en ella; problema que, a veces, se hace insalvable partiendo de que médicos y juristas no comprenden lo mismo bajo idéntico concepto (Yáñez, 1970:320).

La imputabilidad disminuida o semiimputabilidad es una fórmula vacía. ¿Es acaso el imputable disminuido más imputable que inimputable o es más bien más inimputable que imputable?, ¿Cuál es el límite si el legislador no establece cómo debe ser esa disminución?

La imputabilidad disminuida es sinónimo de capacidad mental parcial o incompleta. Bajo este concepto, no se hace distinción en cuanto a la intensidad de la disminución, por lo que es posible aplicar la misma respuesta penal independientemente de si la disminución fue "significativa" o "poco significativa".

Como se ha expuesto el concepto de imputabilidad disminuida es vago. Véase que la consecuencia penal es muy distinta en países como Chile, España y Costa Rica.

Resulta conveniente replantear la respuesta para los casos en que la persona adulta sometida al proceso penal presenta una disminución de sus capacidades mentales a causa de enfermedad mental, desarrollo psíquico incompleto o retardado, grave perturbación de la conciencia u otras anomalías o alteraciones mentales, tomando en cuenta que la imputabilidad disminuida es sinónimo de capacidad mental parcial o incompleta, indistintamente de la intensidad de la disminución, ${ }^{6}$ siendo relevante que si una persona presenta una disminución en su capacidad se indague en qué consiste esta, a efectos de concluir si posee capacidad suficiente para comprender el carácter ilícito de los hechos o de adecuarse a esa comprensión (imputable) o, si por el contrario, la disminución le impidió tener capacidad suficiente a nivel cognoscitivo y/o volitivo (inimputable).

\footnotetext{
6 Sobre este punto véase Harbottle (2012:180-231), obra en la que se realizó un análisis estructurado de 64 sentencias dictadas en Costa Rica, emitidas en sede de casación y revisión en el período 1990-2011, en las que se alegó que la persona adulta acusada actuó bajo un estado de imputabilidad disminuida, determinándose que en 60 de ellas (94\%) no se dejó constancia de que el Tribunal Penal de Juicio realizara una fundamentación sobre la disminución en las capacidades mentales alegada por las partes previo al dictado del fallo.
} 
Con base en lo estudiado, se propone la eliminación del concepto de imputabilidad disminuida de la teoría del delito a partir de una redefinición de los términos imputabilidad e inimputabilidad.

Se estima oportuno que en las legislaciones se entienda por inimputable a quien "...en el momento de la acción u omisión no posea capacidad suficiente para comprender el carácter ilicito del hecho o de determinarse de acuerdo con esa comprensión por causa de enfermedad mental, de desarrollo psíquico incompleto o retardado, de una grave perturbación de la conciencia, o por cualquier otra anomalía o alteración mental" y por imputable a quien "...aún cuando tenga una enfermedad mental, un desarrollo psíquico incompleto o retardado, una perturbación de la conciencia, o cualquier otra anomalia o alteración mental, en el momento de la acción u omisión posea capacidad suficiente para comprender el carácter ilícito del becho y de determinarse de acuerdo con esa comprensión".

Se visualizan dos posibles críticas a nuestro planteamiento.

a) La imputabilidad es graduable. En los casos de disminución de capacidad, es posible determinar su grado; de ahí la necesidad del término imputabilidad disminuida.

Se responde esta idea indicando que nuestra propuesta no niega que la capacidad mental es graduable (incluso, una disminución de la misma). Nuestro planteamiento viene a exigir un análisis más exhaustivo de esa graduación a efectos de inscribirla, ya sea bajo el nuevo concepto de imputabilidad o, por el contrario, al de inimputabilidad debiendo fundamentarse si realmente la misma impidió o imposibilitó que la persona tuviese suficiente capacidad.

b) Hablar de capacidad suficiente puede llevar a la misma imprecisión terminológica que suele atribuírsele a la imputabilidad disminuida, lo que podría generar inseguridad jurídica.

Se replica este planteamiento argumentando que con la reformulación seguirá considerándose imputable a quien posea plena capacidad e inimputable a quien no la posea, es decir, en este sentido no existe ninguna variación. El cambio se centra en que, ante una disminución de capacidades, tendrá que hacerse un análisis más profundo y cuidadoso, tanto por parte de los peritos como de las y los jueces para los efectos de indagar la relevancia de la misma, lo cual requerirá una adecuada fundamentación del órgano juzgador para determinar si ante esa disminución de la capacidad mental la persona, en el momento de los hechos, estaba o no en una condición apta o idónea que le permitiera comprender el carácter ilícito del hecho y de determinarse de acuerdo con esa comprensión.

Debe verificarse en primer lugar, si desde el punto de vista psicológico o psiquiátrico forense se explica la existencia de una enfermedad mental, un desarrollo psíquico incompleto o retardado, una perturbación de la conciencia u otra anomalía o alteración mental en el momento de los hechos. Luego, en el segundo nivel, debe determinarse la incidencia de esos trastornos mentales (de 
existir) para ese momento en los planos cognoscitivo y volitivo a fin de concluir si la persona tenía capacidad suficiente (imputable) o no (inimputable). ${ }^{7}$

Solamente mediante una redefinición de la imputabilidad (y en su caso, de la inimputabilidad) será legítima la imposición de una pena a una persona que cometió un hecho delictivo habiendo actuado con una disminución no significativa de la capacidad mental por lo que, imponer una sanción a un sujeto que es de cierto modo imputable (pero a su vez parcialmente inimputable), pone en tela de juicio la coherencia de la actual teoría del delito.

La terminología que aquí se propone está asociada a la flexibilidad o adaptabilidad que exige el transcurso del tiempo, la evolución y los avances de las ciencias médicas, la psiquiatría, la psicología clínica y forense. Y ahora diríamos, de las neurociencias.

Este calificativo debe ser analizado no como una medida matemática, sino como una medida normativa sin desvincularse de criterios biológico-psicológicos y psiquiátricos, siempre partiendo de las vertientes cognoscitiva y volitiva.

No podemos olvidar que en el campo del Derecho siempre habrá un mínimo de arbitrio para quien juzga, lo importante es no descender al plano de la arbitrariedad.

\section{Conclusiones}

El concepto de imputabilidad disminuida data del siglo XIX. Ha sido moldeado principalmente por dos corrientes: la Escuela Clásica y la Escuela Positiva. La primera, sostuvo que si las facultades intelectivas y volitivas en un ser humano son disminuidas, debe considerarse que no tiene plena libertad para elegir (libre albedrío) y, por lo tanto, si comete una conducta sancionada como delito, le corresponde una responsabilidad y una pena atenuada. En cambio para la Escuela Positiva, fundada en el determinismo y la defensa social, las personas que delinquen con menor culpabilidad son más peligrosas (peligrosidad) que quienes poseen plena aptitud para delinquir y, por lo tanto, resulta absurdo una atenuación de su sanción.

\footnotetext{
${ }^{7} \mathrm{Al}$ respecto, la Sala de Casación Penal costarricense ha sido clara al indicar que en lo que respecta al tema de la inimputabilidad y de la imputabilidad disminuida, lo que el sistema penal requiere de los peritos de psiquiatría y psicología forense es un diagnóstico, no correspondiéndole a los peritos forenses emitir valoraciones acerca de la incidencia que tienen los anteriores supuestos sobre la capacidad de comprensión y sobre la capacidad de acción e inhibición de un sujeto en relación con el ilícito concreto por el cual está siendo juzgado; sencillamente porque este segundo componente o nivel del concepto es de carácter normativo-valorativo, lo cual significa que le compete exclusivamente al juzgador (Sala Tercera de la Corte Suprema de Justicia de Costa Rica, sentencia $\mathrm{n}^{\circ}$ 2013-00739 de las 11:13 horas del 14 de junio de 2013).
} 
En términos generales, puede decirse que ambas escuelas coinciden en definir la imputabilidad como total capacidad mental (capacidad plena); a la inimputabilidad como total incapacidad mental (ausencia de capacidad) y a la imputabilidad disminuida como capacidad mental incompleta o disminuida. Estos conceptos mantienen vigencia en la actualidad.

La capacidad mental disminuida fue visualizada en el clasicismo únicamente a partir de los estados morbosos o enfermedades; la corriente positivista fue más allá, al contemplar también otras situaciones como los denominados trastornos de la conciencia.

La doctrina penal sostiene actualmente un debate sobre la conveniencia de regular en los ordenamientos jurídicos el instituto de la imputabilidad disminuida. Los partidarios de su eliminación, afirman que la indeterminación del concepto conlleva al riesgo de que quien juzga incluya de forma indiscriminada dentro de esta categoría los supuestos dudosos y que se enmarcan entre la culpabilidad y la peligrosidad. Quienes sostienen que este término debe mantenerse vigente, aseveran que la capacidad mental de las personas tiene grados, por lo que la imputabilidad disminuida debe estar en medio de la imputabilidad y de la inimputabilidad.

A nivel doctrinario se han expuesto diversos planteamientos en relación con la respuesta que debe ofrecer el Derecho Penal para los supuestos en que se demuestra que una persona adulta cometió un hecho sancionado como delito, actuando bajo un estado de imputabilidad disminuida. Se ha hablado de la imposición de una pena de prisión atenuada, la imposición de medidas de seguridad (al igual que ocurre con la inimputabilidad) e incluso la posibilidad de imponer tanto pena de prisión como medida de seguridad en el orden señalado por el Tribunal.

En el presente artículo, se ha presentado como propuesta la eliminación de la imputabilidad disminuida -a partir de una redefinición de los conceptos de imputabilidad e inimputabilidad- básicamente por cuanto este instituto jurídico es sinónimo de capacidad mental parcial o incompleta, indistintamente de la intensidad de la disminución. Bajo la nueva fórmula que se plantea se sigue considerando imputable a quien posea plena capacidad e inimputable quien no la posea, es decir, en este sentido no hay ninguna variación. El cambio radica en que a partir de ahora ante una disminución de capacidades, en el dictamen pericial deberá hacerse un análisis más profundo, cuidadoso y detallado que venga a explicar en qué consiste esa disminución y, por otra parte, quien juzga deberá determinar -con base en esta prueba y los demás elementos probatorios existentes- si en el momento del hecho la persona imputada tenía o no capacidad suficiente para comprender su carácter ilícito o de determinarse de acuerdo con esa comprensión. 


\section{BIBLIOGRAFÍA}

* Arias EIBE, Manuel (2007): Responsabilidad Criminal. Circunstancias modificativas y su fundamento en el Código Penal. Una visión desde la doctrina y la jurisprudencia del Tribunal Supremo, Editorial Bosch, Barcelona.

* Armaza Armaza, Emilio (2013): El Tratamiento Penal del Delincuente Imputable Peligroso, Editorial Comares, Granada.

* Arocena, Gustavo, BALCARCE, Fabián y CESANO, José (2015): Derecho penal y neurociencias, Hammurabi, Buenos Aires.

* Bacigalupo, Enrique (1999): Derecho Penal. Parte General, Editorial Hammurabi S.R.L., Buenos Aires.

* Cabello, Vicente (1981): Psiquiatría forense en el derecho penal, volumen I, Editorial Hammurabi S.R.L., Buenos Aires.

* Calderón CADAvid, Leonel (1996): La inimputabilidad en el derecho penal y en el procedimiento, Temis, Bogotá.

* Carmona Castillo, Gerardo (1995): La imputabilidad penal, Porrúa, México.

* Castillo González, Francisco (2010): Derecho Penal. Parte General. Tomo II, Editorial Jurídica Continental, San José, Costa Rica.

* Chan Mora, Gustavo (2013): "Capacidad de Culpabilidad y Libertad de Decisión. Acerca del Debate entre las Neurociencias, la Filosofía de la Mente y el Derecho Penal”, Revista Digital de la Maestría en Ciencias Penales, $\mathrm{N}^{\circ}$ 5: 78-114, en: http://revistas.ucr.ac.cr/index.php/RDMCP/article/view/12439/11693

* Chinchilla Calderón, Rosaura (2010): Principio de legalidad ¿muro de contención o límite difuso para la interpretación de la teoría del delito en C.R.? Investigaciones Jurídicas, S.A., San José, Costa Rica.

* Cury Urzúa, Enrique (2007): Derecho Penal, Parte General, Editorial Pontificia Universidad Católica de Chile, Santiago.

* Díaz Palos, Fernando (1965): Teoría General de la Imputabilidad, Editorial Bosch, Barcelona.

* Demetrio Crespo, Eduardo (2015): “Libertad de Voluntad, Investigación sobre el Cerebro y Responsabilidad Penal. Aproximación a los Fundamentos del Moderno Debate sobre Neurociencias y Derecho Penal", Revista Digital de la Maestría en Ciencias Penales, $\mathrm{N}^{\circ} 7$ : 1-52, en: http://revistas.ucr.ac.cr/index.php/RDMCP/article/view/12439/11693.

* Ferreirós, Carlos (2007): Salud mental y derechos bumanos: la cuestión del tratamiento ambulatorio involuntario, Comité Español de Representantes de Personas con Discapacidad-CERMI, Madrid.

* Ferri, Enrico (2005): Sociología Criminal, Valletta Ediciones, Buenos Aires.

* HarbotTle Quirós, Frank (2012): Imputabilidad disminuida. Hacia una redefinición de la imputabilidad e inimputabilidad (con jurisprudencia), Juritexto, San José, Costa Rica.

* JuÁrez LÓPEZ, José (2010): Manual de psicología e investigación criminal. Evaluación psicológica forense de la imputabilidad. Ediciones Pirámide Madrid.

* Leyton JimÉNEZ, José (2014): "El concepto de imputabilidad disminuida a la luz del principio de culpabilidad y del conocimiento contemporáneo de las enfermedades mentales", Revista jurídica del Ministerio Público, ( $\mathrm{N}^{\circ}$ 58). pp. 9-46.

* López Miguel, María y NúÑez Gaitán, María (2014): "Psicopatología y Delincuencia: Implicaciones en el Concepto de Imputabilidad", en: POZUECO ROMERO, José (Coord.), Tratado de Psicopatología Criminal. Psicología Jurídica y Psiquiatría Forense, volumen II: 881-890, Editorial EOS, Madrid.

* Martínez Garay, Lucía (2005): La Imputabilidad Penal: Concepto, Fundamento, Naturaleza Jurídica y Elementos, Tirant lo Blanch, Valencia.

* Morales García, Jorge Luis (2008): "La imputabilidad disminuida", Revista de Ciencias Penales, $\mathrm{N}^{\circ} 25: 125-139$. 
Harbottle - La inimputabilidad disminuida: una categoría problemática del derecho penal

* Muñoz Conde, Francisco (2008): "La imputabilidad desde el punto de vista médico y jurídico penal", Revista de Derecho Penal y Criminología, (N 35). pp. 27-38.

* NÁQuira, Jaime (1987): Estudios Jurídicos sobre la Reforma Penal. Imputabilidad e inimputabilidad en el sistema del Código Penal Tipo para Latinoamérica, Servicio de Publicaciones Universidad de Córdoba, Córdoba.

* Navas Aparicio, Alfonso (2011): Código Penal de Costa Rica Comentado, volumen I, Ulacit, San José, Costa Rica.

* Pavón Vasconcelos, Francisco (1983): Imputabilidad e inimputabilidad, Editorial Porrúa, México.

* Puig Peña, Federico (1955): Derecho Penal. Parte General, volumen II, Editorial Revista de Derecho Privado, Madrid.

* Roxin, Claus (1997): Derecho Penal. Parte General. Fundamentos. La Estructura de la Teoría del Delito, Civitas, Madrid.

* Soler, Sebastián (1989): Derecho Penal Argentino, Tipografía Editora Argentina, Buenos Aires.

* Urruela Mora, Asier (2004): Imputabilidad penal y anomalía o alteración psíquica. Editorial Comares, Granada.

* Vela Treviño, Sergio (1988): "La imputabilidad disminuida", Revista Criminalia, (N 1-12). pp. 293-321.

* Velásquez, Fernando (1997): Derecho Penal. Parte General, Temis, Bogotá.

* Yáñez Román, Pedro (1970): "Consideraciones en torno a la imputabilidad disminuida con especial referencia a los psicópatas. Su tratamiento y los denominados establecimientos de terapéutica social", Anuario de Derecho Penaly Ciencias Penales, (N 23). pp. 301-390.

* Zaffaroni, Eugenio (2002): Derecho Penal, Parte General, Ediar, Buenos Aires.

* ZaZZALi, Julio (2015): Psiquiatría Forense, Ediciones La Rocca, Buenos Aires.

\section{JURISPRUDENCIA CITADA}

* Sala Tercera de la Corte Suprema de Justicia de Costa Rica (2013): Resolución n. ${ }^{\circ}$ 201300739 de las 11:13 horas del 14 de junio de 2013.

* Sala Constitucional de la Corte Suprema de Justicia de Costa Rica (2010): Resolución n. ${ }^{\circ}$ 2010-17720 de las 14:32 horas del 26 de octubre de 2010.

* Sala Constitucional de la Corte Suprema de Justicia de Costa Rica (2010): Resolución n. ${ }^{\circ}$ 2010-12189 de las 17:12 horas del 20 de julio de 2010.

* Sala Constitucional de la Corte Suprema de Justicia de Costa Rica (2009): Resolución n. ${ }^{\circ}$ 2009-04555 de las 08:23 horas del 20 de octubre de 2009.

* Sala Constitucional de la Corte Suprema de Justicia de Costa Rica (2009): Resolución n. ${ }^{\circ}$ 2009-10383 de las 13:39 horas del 26 de junio de 2009.

\section{NORMAS JURÍDICAS CITADAS}

* Código Penal. República de Costa Rica (2015): Ley no 4573 del 4 de mayo de 1970. San José: Editorial Investigaciones Jurídicas S.A.

* Código Penal de la Nación Argentina (2013): La Plata-Buenos Aires: Editorial Lex.

* Código Penal de España y legislación complementaria (2015). Madrid: Agencia Estatal Boletín Oficial del Estado.

* Código Penal Alemán (1999): En C. López Díaz (traductora), Traducción del Strafgesetz̧buch (1998). Bogotá: Universidad Externado de Colombia. Disponible en https://www.unifr.ch/ddp1/derechopenal/obrasjuridicas/oj_20080609_13.pdf 